\title{
Exstrophy-Epispadias Complex in a Newborn: Case Report and Review of the Literature
}

\author{
Enrico Valerio, MD ${ }^{1}$ Valentina Vanzo, MD ${ }^{1}$ Patrizia Zaramella, $\mathrm{MD}^{1} \quad$ Sabrina Salvadori, MD ${ }^{1}$ \\ Marco Castagnetti, MD ${ }^{2}$ Eugenio Baraldi, MD ${ }^{1}$ \\ ${ }^{1}$ Department of Woman and Child Health, Neonatal Intensive Care \\ Unit, Medical School, University of Padua, Padova, Italy \\ 2 Section of Pediatric Urology, Urology Unit, University Hospital of \\ Address for correspondence Enrico Valerio, MD, Department of \\ Woman and Child Health, Medical School, University of Padua, Via \\ Giustiniani, 3, 35128 Padova, Italy \\ Padova, Padua, Italy \\ (e-mail: enrico.valerio.md@gmail.com; enrico.va@inwind.it).
}

Am J Perinatol Rep 2015;5:e183-e187.

\begin{abstract}
Keywords

- exstrophy-epispadias complex

- neonatology

- newborn

- congenital disease

- urology

Aim The aim of this report is to present a brief review of the current literature on the management of EEC.

Case Report A term male neonate presented at birth with classic bladder exstrophy, a variant of the exstrophy-epispadias complex (EEC). The defect was covered with sterile silicon gauzes and waterproof dressing; at 72 hours of life, primary closure without osteotomy of bladder, pelvis, and abdominal wall was successfully performed.

Discussion EEC incidence is approximately 2.15 per $1,00,000$ live births; several urological, musculocutaneous, spinal, orthopedic, gastrointestinal, and gynecological anomalies may be associated to EEC. Initial medical management includes use of occlusive dressings to prevent air contact and dehydration of the open bladder template. Umbilical catheters should not be positioned. Surgical repair stages include initial closure of the bladder and abdominal wall with or without osteotomy, followed by epispadias repair at 6 to 12 months, and bladder neck repair around 5 years of life. Those who fail to attain continence eventually undergo bladder augmentation and placement of a catheterizable conduit.

Conclusion Modern-staged repair of EEC guarantees socially acceptable urinary continence in up to $80 \%$ of cases; sexual function can be an issue in the long term, but overall quality of life can be good.
\end{abstract}

A male newborn was delivered vaginally at $38^{5 / 7}$ weeks. Pregnancy was uneventful, and no fetal anomalies were detected at prenatal ultrasound controls. Maternal serologies for HbsAg, HCV, HIV, Toxoplasma, and Rubella were negative, as was vaginal swab. Delivery was not complicated and Apgar Score was 9 at 1 st, 9 at 5th, and 10 at 10th minute of life. The neonate presented at birth with a genitourinary defect consistent with the classic bladder exstrophy variant of the exstrophy-epispadias complex (EEC). Exposed, everted bladder template was clearly visible immediately below umbilical stump; a completely dorsally opened (epispadic) urethral

received

January 17, 2015

accepted after revision

May 19, 2015

published online

September 7, 2015 plate run from bladder neck down to the open glans; left and right corpora cavernosa were clearly visible beneath and alongside urethral plate; the scrotum was normally developed, but caudally displaced; anus was normal (-Fig. 1). Physical examination was otherwise unremarkable. The defect was covered in delivery room with sterile silicon gauzes and transparent waterproof dressing. Prudently, no umbilical vascular catheters were positioned at birth. Cerebral, cardiac, abdominal, and kidney ultrasound were then performed, turning out to be normal. Pelvic ultrasound esteemed a pubic symphysis diastasis of $28 \mathrm{~mm}$. At 72 hours of life, primary
Copyright $\odot 2015$ by Thieme Medical Publishers, Inc., 333 Seventh Avenue, New York, NY 10001, USA. Tel: +1(212) 584-4662.
License terms

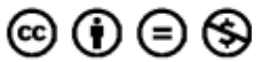

10.1055/s-0035-1556759. ISSN 2157-7005. 


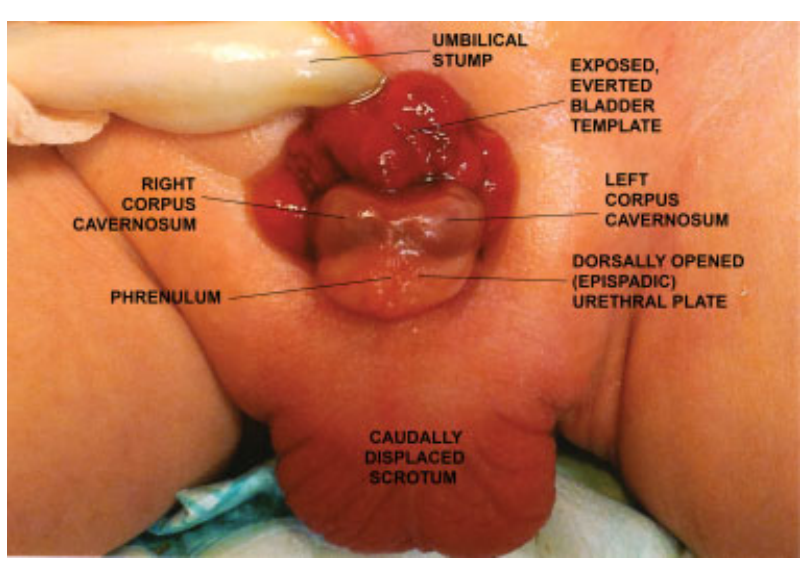

Fig. 1 Male newborn with classic bladder exstrophy. Exposed, everted bladder template is clearly visible immediately below umbilical stump; a completely dorsally opened (epispadic) urethral plate runs from bladder neck down to the open glans; left and right corpora cavernosa are visible beneath and alongside urethral plate; the scrotum is caudally displaced.

closure of bladder, pelvis, and abdominal wall was performed successfully, without pelvic osteotomy. Two ureteral catheters, one transurethral catheter and an epicystostomy tube were left indwelling. In the first 5 postoperative days, the patient was kept immobilized with pelvis and lower limbs wrapped around and suspended in a special hammock device (modified Bryant traction) (-Fig. 2). ${ }^{1}$ Parenteral nutrition was administered during this period. Curarization was maintained for the first 5 days after surgery; systemic sedoanalgesia was gradually tapered, and ultimately stopped 10 days after surgery. Full enteral feeding was restored at day 10 postoperatively. A perirenal urinoma was registered as a postoperative complication. Tubes were sequentially removed during the fourth postoperative week, and patient was discharged on postoperative day 28. Patient was kept in a thoracopelvic orthosis for the first 2 month of life. ${ }^{2}$ Further surgery for epispadias repair is scheduled at the age of 9 months of life.

\section{Discussion}

\section{What is Exstrophy-Epispadias Complex}

EEC encompasses a spectrum of pathologies going from isolated epispadias, to classic bladder exstrophy, to cloacal exstrophy as the most severe-and rarest-presentation. ${ }^{3}$ Next to the bladder, the malformation involves the genitalia, the abdominal wall muscles, the pelvic floor musculature, and the bony pelvis. ${ }^{4}$

\section{Epidemiology}

The overall incidence of EEC has been estimated by Nelson et $\mathrm{al}^{5}$ in 2.15 per 100,000 live births, with an even male-tofemale ratio (odds ratio, $0.989 ; 95 \%$ confidence interval 0.88 1.12 ), and a significantly increased incidence in white compared with nonwhite neonates (incidence, 2.63 vs. 1.54 per $100,000 ; p<0.0001)$. Classic bladder exstrophy occurs in $1: 10,000$ to $1: 50,000$ live births ${ }^{6}$; epispadias is estimated to

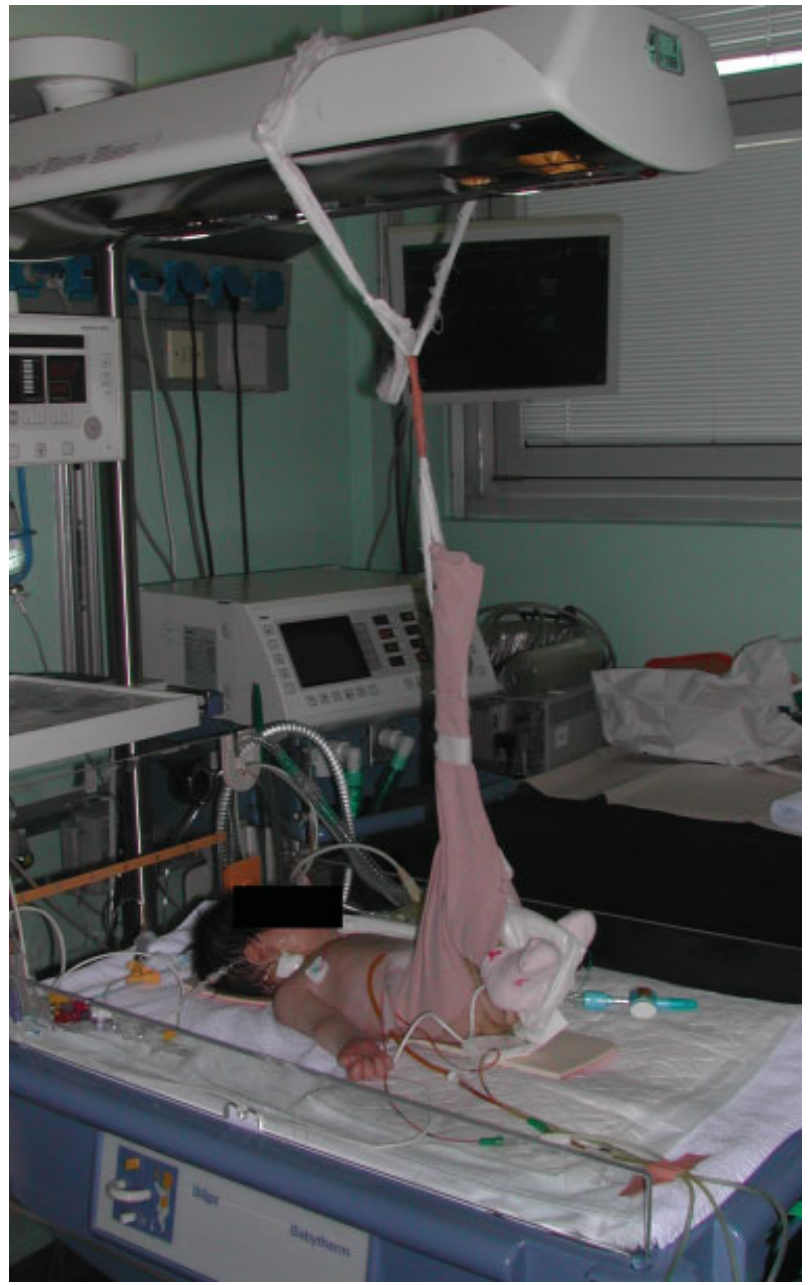

Fig. 2 Postoperative patient immobilization with pelvis and lower limbs wrapped around and suspended in a special hammock device (modified Bryant traction).

occur in 1:117,000 live births, and cloacal exstrophy in $1: 250,000$ births. $^{7}$

\section{Embryology and Associated Conditions}

EEC derives from a derangement in mesodermal layers fusion during the first weeks of fetal life. Normally, at the end of third week of gestation, intermediate layer of mesoderm starts to invaginate to give origin to the urogenital system, while the lateral plate mesoderm will contribute in forming the primitive gut tube. ${ }^{3} \mathrm{~A}$ disruption in this interaction, possibly related to a cloacal membrane overgrowth preventing medial migration of mesenchymal tissue, is reported to give origin to $\mathrm{EEC}^{8}$; severity of the resulting condition depends on the point at which disturbed mesodermal layers interaction begins.

Given the embryological origin of the disorder, EEC is often associated with other peculiar orthopedic, musculocutaneous, and gynecological conditions. Associated upper urinary tract anomalies are rare. Gastrointestinal and spinal/neurological anomalies can be associated in patients with cloacal exstrophy (-Table 1). ${ }^{3,4,9}$ 
Table 1 EEC-commonly associated conditions

\begin{tabular}{|l|}
\hline Urological \\
\hline Stenosis/obstruction of the ureteropelvic junction \\
\hline Vesicoureteral reflux \\
\hline Ectopic kidney \\
\hline Horseshoe kidney \\
\hline Renal dysplasia/agenesis \\
\hline Megaureter \\
\hline Ureteral ectopy \\
\hline Ureterocele \\
\hline Musculocutaneous \\
\hline Abdominal wall defects \\
\hline Divergent distal rectus abdominis muscles \\
\hline Umbilical hernia \\
\hline Spinal/neurological \\
\hline Neural tube defects \\
\hline Vertebral anomalies \\
\hline Myelodysplasia and/or myelomeningocele \\
\hline Dysraphism \\
\hline Tethered cord \\
\hline Orthopedic \\
\hline Clubfoot deformities \\
\hline Absence of feet \\
\hline Tibial or fibular deformities \\
\hline Hip dislocations \\
\hline Pubic symphysis gap \\
\hline Open-book configuration of the pelvis \\
\hline Gastrointestinal \\
\hline Common hindgut remnant \\
\hline Anteriorly displaced anus \\
\hline Imperforate anus \\
\hline Rectal stenosis \\
\hline Rectal prolapse \\
\hline Omphalocele \\
\hline Gastrointestinal malrotation/duplication \\
\hline Short bowel syndrome \\
\hline Duodenal atresia \\
\hline
\end{tabular}

Abbreviation: EEC, exstrophy-epispadias complex.

\section{Medical and Surgical Management}

Immediate medical management of EEC consists of covering the extruding viscera with sterile silicon gauzes plus a surmounting occlusive dressing to prevent air contact and dehydration of the exstrophic plaque. Umbilical catheters should not be positioned. No prophylactic antibiotic therapy is mandatory at birth if no physical signs of infection are detectable; on the contrary, postoperative prophylactic antibiotic treatment is advisable to avoid potential postoperative complications (see section "Long-Term Complications and Outcome").

Surgical correction varies depending on the type and severity of the defect; most of the neonates, however, will need closure of the bladder and abdominal wall, repair of epispadias, ureteral reimplantation, and bladder neck repair. Some of them will also require pelvic osteotomy to facilitate relaxation of the abdominal wall during closure. Osteotomy might possibly also improve functional outcomes of genitourinary reconstruction. ${ }^{10}$ Criteria proposed to select cases requiring an osteotomy include patients undergoing closure after 72 hours of life, when the pelvis becomes more stiff, those with a pubic diastasis wider than $4 \mathrm{~cm}$, and those with a nonmalleable pelvis. Under these circumstances, the osteotomy is performed at the same time as exstrophy closure (i.e., combined pelvic osteotomy). ${ }^{11}$ In patients with extremely wide pubic diastases $(>6 \mathrm{~cm}$, most often associated with cloacal exstrophy), a strategy involving osteotomy before bladder closure (i.e., staged pelvic osteotomy) has been proposed to allow gradual reduction in diastasis with slow stretching of pelvic soft tissue. ${ }^{12}$

Postoperatively, management key factors for the success of closure include immobilization and traction of the lower limbs, appropriate urinary drainage, curarization, analgesia (also using epidural catheters when possible), broad-spectrum antibiotic prophylaxis, and parenteral nutrition.

Currently, a staged approach is the strategy most commonly used. Alternatively, the neonatal primary complete repair and the deferred primary complete repair have been proposed. ${ }^{13,14}$ In the standard-staged repair, a primary closure of the bladder without osteotomy, and without genital reconstruction in males, is attempted in the first 72 hours of life; between 6 and 12 months of age, the epispadias repair is performed in males. Bladder neck reconstruction follows around the age of 5 years, if a reasonable bladder capacity is reached.

Patients whose bladders fail to grow before bladder neck reconstruction (to at least $100 \mathrm{~mL}$ of capacity), or fail keep growing after bladder neck reconstruction thereby causing persistent incontinence or upper urinary tract deterioration, are candidate to undergo augmentation cystoplasty. A segment of sigmoid colon or ileum can be used to augment the bladder. $^{15}$

Augmented bladders generally lose the ability to empty volitionally to completion; therefore, periodical clean intermittent catheterizations become necessary. As the reconstructed urethra is unreliable for catheterization, bladder augmentation is combined with placement of a catheterizable conduit bridging the bladder to the skin. The conduit can be created using the appendix (i.e., Mitrofanoff appendicovesicostomy) or a 2 to $3 \mathrm{~cm}$ long segment of ileum (i.e., Monti ileovesicostomy) and 
should be patent to a $12-14$ Ch tube. ${ }^{16}$ The most common complications include stomal stenosis and urinary leakage via the conduit. ${ }^{17}$ The appendix is generally less keen than is the ileal tissue to develop complications. ${ }^{18}$

\section{Long-Term Complications and Outcome}

Modern-staged repair of the EEC as previously described has shifted the goal from patient's survival to quality of life. The single most important outcome in bladder exstrophy repair is probably urinary continence, ${ }^{18}$ which is more easily achieved with successful primary bladder closure and good bladder growth. ${ }^{19}$ The latter occurs as an adaptation of the bladder wall to the increase in bladder outlet resistances after bladder closure and after bladder neck reconstruction. Of note, this increase in resistances should never happen at the cost of upper urinary tract deterioration, which may occur in case of poorly compliant bladders with incomplete emptying. ${ }^{20} \mathrm{Re}-$ portedly, up to $80 \%$ of cases can achieve a socially acceptable urinary continence (3-hour dry interval during daytime and volitional voiding) using this surgical strategy. ${ }^{21}$ Nevertheless, many series report that 20 to $50 \%$ of cases will require bladder augmentation eventually. ${ }^{15}$

Genital function keeps being a relevant problem in patients with exstrophy long term. Males can experience problems for the presence of a short penis or persistent penile curvature. $^{22}$

Excessive bladder-neck tapering may cause seminal obstruction and recurrent epididymitis leading to infertility. Female patients can experience problems because of the abnormal genital appearance, stenosis of the vaginal introitus, and pelvic organ prolapse. ${ }^{23}$ These problems, however, do not generally impair a good quality of life. ${ }^{24}$

Although patients with exstrophy have almost invariably an abnormal gait in the long term because of the recurrence of the pelvic diastasis, which invariably recurs also in patients undergoing osteotomy, long-term orthopedic complications are rare. ${ }^{25}$ Patients receiving an osteotomy may experience transient of persistent nerve damage, hip pain, and unequal length of limbs. ${ }^{26}$

\section{Conclusion}

Reportedly, modern-staged repair of EEC can achieve a socially acceptable urinary continence (3-hour dry interval during daytime and volitional voiding) in up to $80 \%$ of cases after successful primary closure ${ }^{21}$; sexual function can be an issue in the long term (particularly in males), ${ }^{22,23}$ but overall quality of life can be good. ${ }^{24}$

\section{Conflicts of Interest \\ None.}

\section{References}

1 Meldrum KK, Baird AD, Gearhart JP. Pelvic and extremity immobilization after bladder exstrophy closure: complications and impact on success. Urology 2003;62(6):1109-1113
2 Castagnetti M, Berrettini A, Beniamin F, Rigamonti W. Thoracopelvic orthosis: a portable and removable bassinet for secure patient immobilization after primary bladder exstrophy closure. Pediatr Surg Int 2010;26(12):1229-1232

3 Stec AA. Embryology and bony and pelvic floor anatomy in the bladder exstrophy-epispadias complex. Semin Pediatr Surg 2011; 20(2):66-70

4 Inouye BM, Tourchi A, Di Carlo HN, Young EE, Gearhart JP. Modern management of the exstrophy-epispadias complex. Surg Res Pract 2014;2014:587064

5 Nelson CP, Dunn RL, Wei JT. Contemporary epidemiology of bladder exstrophy in the United States. J Urol 2005;173(5): 1728-1731

6 Lattimer JK, Smith MJ. Exstrophy closure: a followup on 70 cases. J Urol 1966;95(3):356-359

7 Evans JA, Darvill KD, Trevenen C, Rockman-Greenberg C. Cloacal exstrophy and related abdominal wall defects in Manitoba: incidence and demographic factors. Clin Genet 1985;27(3): 241-251

8 Pierre K, Borer J, Phelps A, Chow JS. Bladder exstrophy: current management and postoperative imaging. Pediatr Radiol 2014; 44(7):768-786, quiz 765-767

9 Ebert AK, Reutter H, Ludwig M, Rösch WH. The exstrophy-epispadias complex. Orphanet J Rare Dis 2009;4:23

10 Jones D, Parkinson S, Hosalkar HS. Oblique pelvic osteotomy in the exstrophy/epispadias complex. J Bone Joint Surg Br 2006;88(6): 799-806

11 Baird AD, Sponseller PD, Gearhart JP. The place of pelvic osteotomy in the modern era of bladder exstrophy reconstruction. J Pediatr Urol 2005;1(1):31-36

12 Inouye BM, Tourchi A, Di Carlo HN, et al. Safety and efficacy of staged pelvic osteotomies in the modern treatment of cloacal exstrophy. J Pediatr Urol 2014;10(6):1244-1248

13 Massanyi EZ, Gearhart JP, Kost-Byerly S. Perioperative management of classic bladder exstrophy. Res Rep Urol 2013;5:67-75

14 Mitchell ME. Bladder exstrophy repair: complete primary repair of exstrophy. Urology 2005;65(1):5-8

15 Woodhouse CR, North AC, Gearhart JP. Standing the test of time: long-term outcome of reconstruction of the exstrophy bladder. World J Urol 2006;24(3):244-249

16 Stewart D, Inouye BM, Goldstein SD, et al. Pediatric surgical complications of major genitourinary reconstruction in the exstrophy-epispadias complex. J Pediatr Surg 2015;50(1): $167-170$

17 Inouye BM, Shah BB, Massanyi EZ, et al. Urologic complications of major genitourinary reconstruction in the exstrophy-epispadias complex. J Pediatr Urol 2014;10(4):680-687

18 Ebert AK, Schott G, Bals-Pratsch M, Seifert B, Rösch WH. Longterm follow-up of male patients after reconstruction of the bladder-exstrophy-epispadias complex: psychosocial status, continence, renal and genital function. J Pediatr Urol 2010; 6(1):6-10

19 Novak TE, Costello JP, Orosco R, Sponseller PD, Mack E, Gearhart JP. Failed exstrophy closure: management and outcome.J Pediatr Urol 2010;6(4):381-384

20 Mouskou S, Dionysis TT, Aivazoglou T, Kapouleas GP. Long-term follow up of complete bladder exstrophy repair. A case report. Folia Med (Plovdiv) 2014;56(1):60-63

21 Gearhart JP, Mathews RI. Exstrophy-epispadias complex. In: Wein AJ, Kavoussi LR, Novick AC, Partin AW, Peters CA, eds. CampbellWalsh Urology, vol. 4, 10th edition. Philadelphia, PA: Elsevier; 2012:3325-3378

22 Woodhouse CR. Sexual function in boys born with exstrophy, myelomeningocele, and micropenis. Urology 1998;52(1):3-11

23 Castagnetti M, Berrettini A, Zhapa E, Rigamonti W, Zattoni F. Issues with the external and internal genitalia in postpubertal females 
born with classic bladder exstrophy: a surgical series. J Pediatr Adolesc Gynecol 2011;24(1):48-52

24 Gupta AD, Goel SK, Woodhouse CR, Wood D. Examining long-term outcomes of bladder exstrophy: a 20-year follow-up. BJU Int 2014; 113(1):137-141

25 Castagnetti M, Gigante C, Perrone G, Rigamonti W. Comparison of musculoskeletal and urological functional outcomes in patients with bladder exstrophy undergoing repair with and without osteotomy. Pediatr Surg Int 2008;24(6):689693

26 Kouame BD, Kouame GS, Sounkere M, et al. Aesthetic, urological, orthopaedic and functional outcomes in complex bladder exstrophy-epispadias's management. Afr J Paediatr Surg 2015;12(1): $56-60$ 